\title{
Mesoporous Spherical Aggregates of Anatase Nanocrystals with Wormhole-like Framework Structures: Their Chemical Fabrication, Characterization and Photocatalytic Performance
}

\author{
Hui Wang ${ }^{a \dagger}$, Jian-Jun Miao ${ }^{\mathrm{a}}$, Jian-Min Zhu ${ }^{\mathrm{b}}$, Hong-Min $\mathrm{Ma}^{\mathrm{a}}$, Jun-Jie Zhu ${ }^{\mathrm{a} *}$, and \\ Hong-Yuan Chen ${ }^{\mathrm{a}}$ \\ ${ }^{a}$ Department of Chemistry, Laboratory of Life Analytical Chemistry, Nanjing University, \\ Nanjing 210093, China \\ ${ }^{b}$ National Laboratory of Solid State of Microstructures, Nanjing University, \\ 210093, China
}

Email:jjzhu@nju.edu.cn

The L-H treatment is known to be a good model for the description of solid-gas reactions. Extrapolation of this model to solid-liquid reactions requires some modifications, especially when the surface is that of $\mathrm{TiO}_{2}$ particles in aqueous solutions; the $\mathrm{TiO}_{2}$ is known to be covered with hydroxyl groups and molecular water. According to the L-H model, the rate of a unimolecular surface reaction, $\mathrm{R}$, is proportional to the surface coverage, $\theta$ and will follow Eqn. (1), when the reactant is more strongly adsorbed on the surface than the products:

$$
\mathrm{R}=-\mathrm{dC} / \mathrm{dt}=\mathrm{k}_{\mathrm{r}} \theta=\mathrm{k}_{\mathrm{r}} \mathrm{KC}_{0} /\left(1+\mathrm{KC}_{0}\right)
$$

where $\mathrm{k}_{\mathrm{r}}$ is the reaction rate constant, $\theta$ is the fraction of the surface covered by the reactant, $\mathrm{K}$ is the adsorption coefficientof the reactant, $\mathrm{C}_{0}$ is the initial concentration of the reactant. Integration of Eqn. (1) yield Eqn. (2):

$$
\ln \left(\mathrm{C}_{0} / \mathrm{C}\right)+\mathrm{K}(\mathrm{Co}-\mathrm{C})=\mathrm{k}_{\mathrm{r}} \mathrm{K} \mathrm{t}
$$

In the present study, since $\mathrm{C}_{0}$ is very small, the equation can be simplified as:

$$
\ln \left(\mathrm{C}_{0} / \mathrm{C}\right)=\mathrm{k}^{\prime} \mathrm{t}
$$

where $\mathrm{k}^{\prime}$ is called apparent first-order rate constant. This reaction can be regarded as a first-order reaction. $\ln (\mathrm{Co} / \mathrm{C})$ vs. reaction time gives a straight line whose slope equals the apparent first-order rate constant k' (See SI_Figure 1). The initial rate equals to $\mathrm{k}^{\prime} \mathrm{C}_{0}$. 


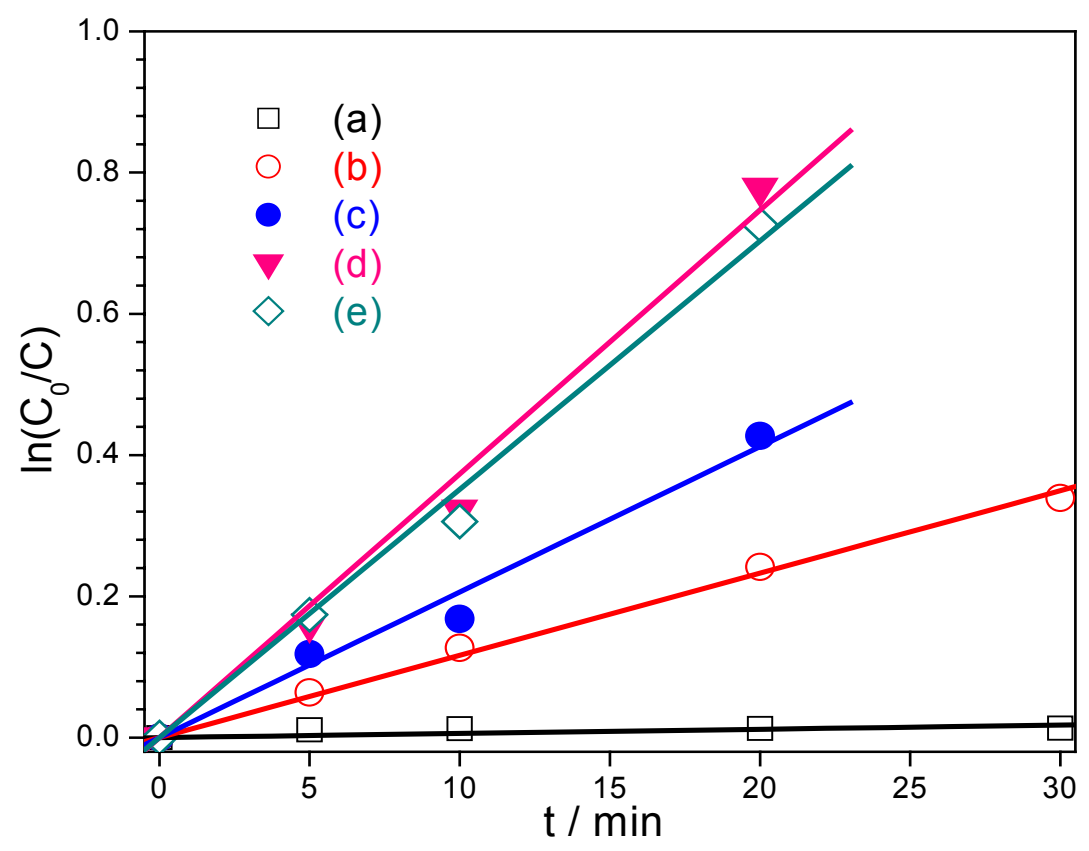

Figure S1

Plots of $\ln \left(\mathrm{C}_{0} / \mathrm{C}\right)$ vs. t. The loadings of mesoporous anatase catalyst are (a) 0 , (b) $1.0 \mathrm{~g} / \mathrm{L}$, (c) $2.0 \mathrm{~g} / \mathrm{L}$, (d) $3.0 \mathrm{~g} / \mathrm{L}$, and (e) $4.0 \mathrm{~g} / \mathrm{L}$. The apparent first-order rate constant $\mathrm{k}$ ' decreases with the increase in the catalyst loading when the catalyst loading is in the range of 0 to $3.0 \mathrm{~g} / \mathrm{L}$ and saturates when the catalyst loading reaches $4.0 \mathrm{~g} / \mathrm{L}$. 
The effect of initial concentration of methyl orange on the photocatalytic degradation rate was investigated over the concentration range of 10.0 to $40.0 \mathrm{mg} / \mathrm{L}$. SI_Figure 2 shows the Plots of $\ln \left(\mathrm{C}_{0} / \mathrm{C}\right)$ vs. $\mathrm{t}$ at different initial methyl orange concentrations with a catalyst loading of $3.0 \mathrm{~g} / \mathrm{L}$.

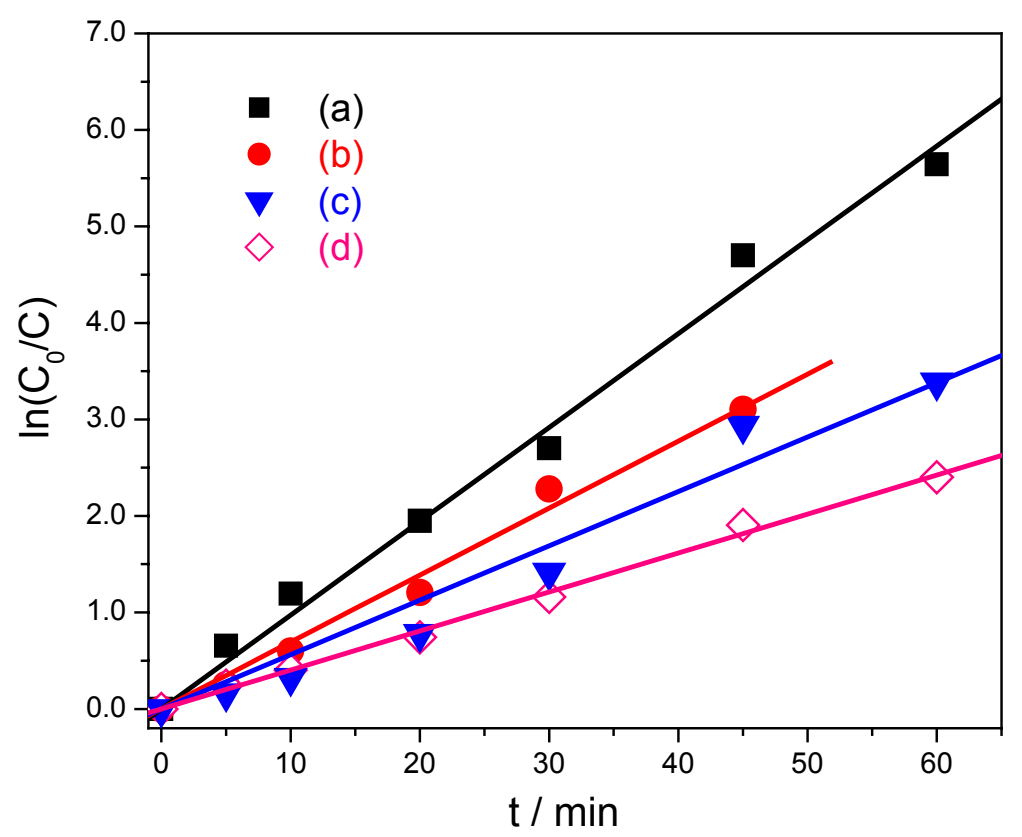

Figure S2

Effect of the initial concentration on photo-degradation of methyl orange. The figure shows the plots of $\ln \left(\mathrm{C}_{0} / \mathrm{C}\right)$ vs. t. The initial concentrations of methyl orange are (a) 10 $\mathrm{mg} / \mathrm{L}$, (b) $20 \mathrm{mg} / \mathrm{L}$, (c) $30 \mathrm{mg} / \mathrm{L}$, and (d) $40 \mathrm{mg} / \mathrm{L}$. The loading of the mesoporous anatase catalyst is $3.0 \mathrm{~g} / \mathrm{L}$. The apparent first-order rate constant k' decreases with the increase in the catalyst loading when the catalyst loading is in the range of 1.0 to $4.0 \mathrm{~g} / \mathrm{L}$. 


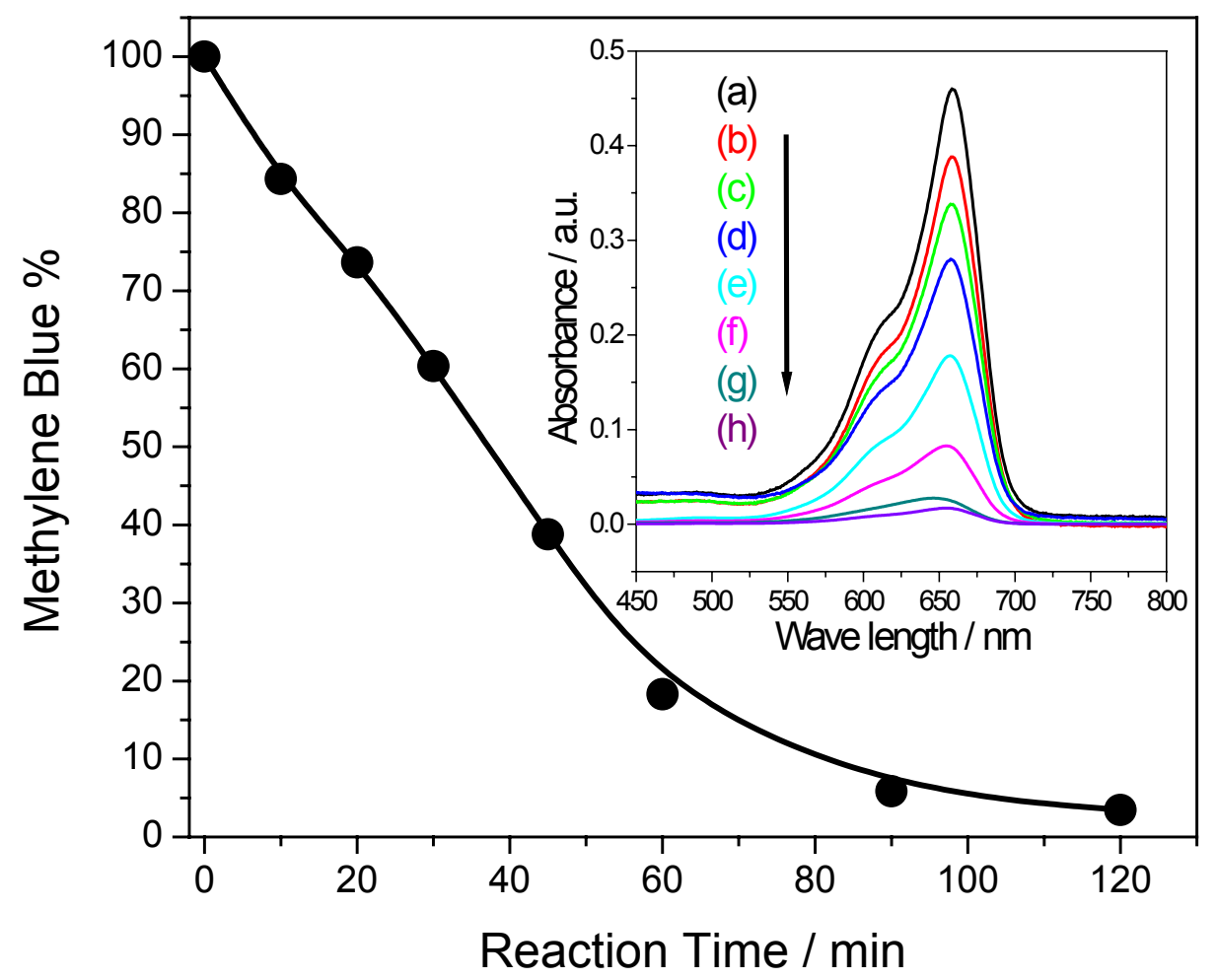

Figure S3

The plots of the amount of methylene blue at different time intervals during the mesoporous anatase catalyzed photo-degradation. The initial concentration of methylene blue is $8.0 \mathrm{mg} / \mathrm{L}$, and the loading of mesoporous anatase catalyst is $3.0 \mathrm{~g} / \mathrm{L}$. The inset is the UV-visible absorption spectra of methylene blue aqueous solution recorded at different time intervals following mesoporous anatase catalyzed photo-degradation. The spectra were recorded at time intervals of: (a) $0 \mathrm{~min}$, (b) $10 \mathrm{~min}$, (c) $20 \mathrm{~min}$, (d) $30 \mathrm{~min}$, (e) $45 \mathrm{~min}$, (f) $60 \mathrm{~min}$, (g) $90 \mathrm{~min}$, (h) $120 \mathrm{~min}$. 


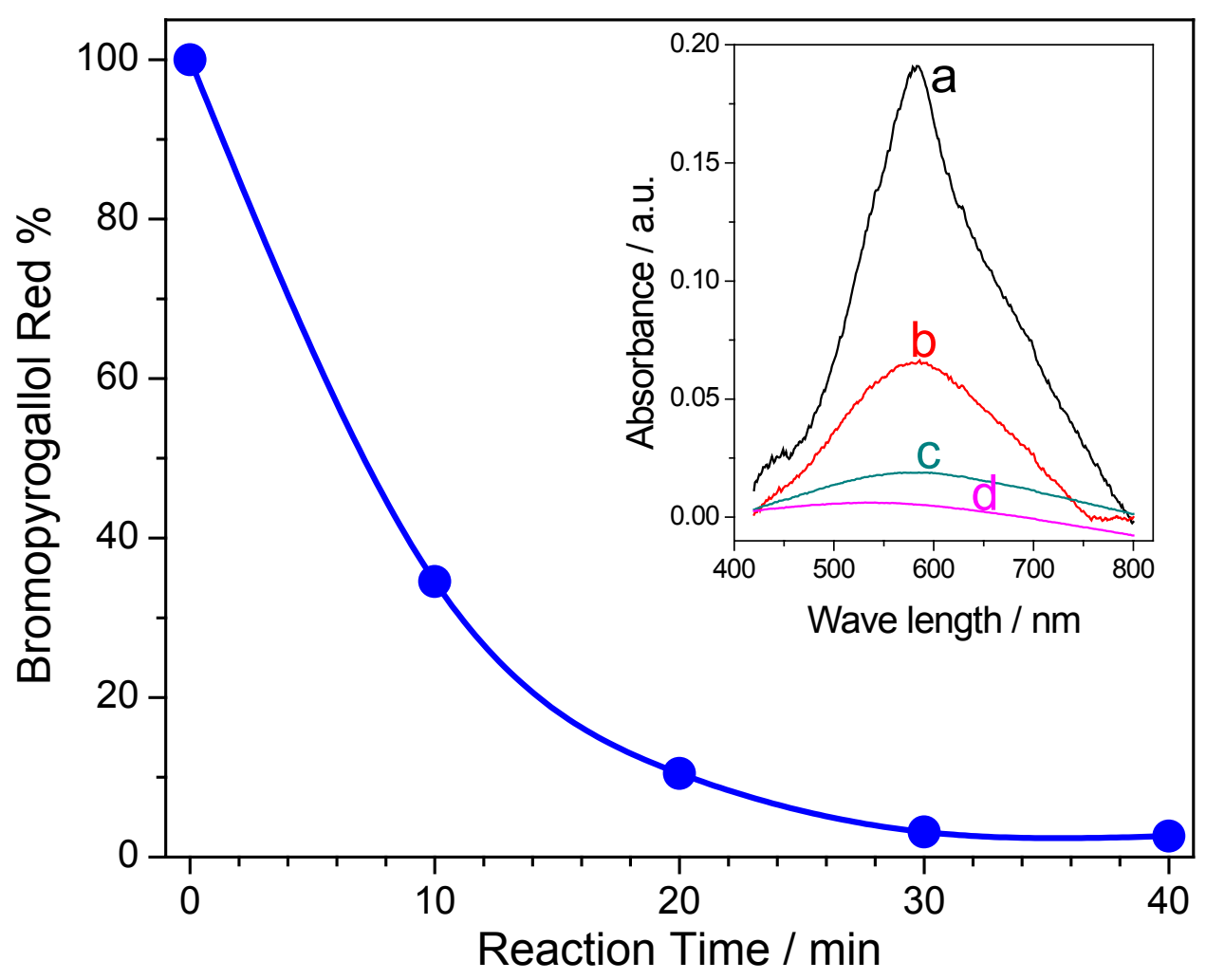

Figure S4

The plots of the amount of bromopyrogallol red at different time intervals during the mesoporous anatase catalyzed photo-degradation. The initial concentration of bromopyrogallol red is $20.0 \mathrm{mg} / \mathrm{L}$, and the loading of mesoporous anatase catalyst is 1.0 $\mathrm{g} / \mathrm{L}$. The inset is the UV-visible absorption spectra of bromopyrogallol red aqueous solution recorded at different time intervals following mesoporous anatase catalyzed photo-degradation. The spectra were recorded at time intervals of: (a) $0 \mathrm{~min}$, (b) $10 \mathrm{~min}$, (c) $20 \mathrm{~min}$, (d) $30 \mathrm{~min}$. 